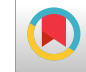

\title{
A Comparison of Policy Analysis of Palliative Care for Cancer in UK, Malaysia, and South Africa
}

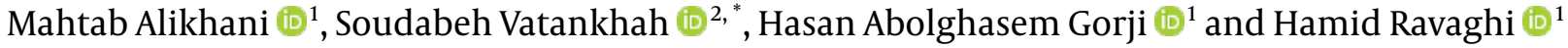 \\ ${ }^{1}$ Department of Health Services Management, School of Health Management and Information Sciences, Iran University of Medical Sciences, Tehran, Iran \\ ${ }^{2}$ Health Management and Economics Research Center, Iran University of Medical Sciences, Tehran, Iran \\ "Corresponding author: Health Management and Economics Research Center, Iran University of Medical Sciences, Tehran, Iran. Email: vatankhahsoudabeh@yahoo.com
}

Received 2019 June 02; Revised 2019 July 20; Accepted 2019 July 23.

\begin{abstract}
Context: Cancer is one of the leading causes of death globally. It changes the patient's life, and not only causes many physical and emotional symptoms but also reduces the quality of life (QOL) in patients during the advanced stages of cancer. Today, the main approach in taking care of these patients is to provide supportive and palliative care with the aim of enhancing the QOL in patients and their families and to reduce the cost of treatment and health care. This study was conducted with the aim of comparing the policies and the strategies related to cancer supportive and palliative care in the selected countries, using the World Health Organization (WHO) guideline in the United Kingdom (UK), Malaysia, and South Africa.

Evidence Acquisition: This study is a comparative study. The data were collected through reviewing scientific and administrative documents, WHO website and reports, the Ministry of health websites, and other authoritative websites. The search was done through texts in English and the databases, including Science Direct, Scopus, and PubMed between 2000 and December 2018. We used a strategy search according to Medical Subject Headings, using the keywords (cancer, palliative care, supportive care, patients, policies, programs, strategies, UK, Malaysia, and South Africa). The data were analyzed by content analysis approach, using MAXQDA software version 11.

Results: The rates of cancer and mortality differed according to the health differences in the selected countries. With regard to palliative care, various policies and programs were implemented. The implementation of more policies was carried out by the Ministry of Health. In some countries, adequate funding was available to support programs. Countries have been trying to provide decent manpower to provide services. Despite the successes achieved in implementing palliative care programs, some factors, such as inadequate healthcare structures and insufficient financial resources have caused problems in implementing programs.

Conclusions: Countries should consider palliative care as one of the important priorities of the health system and a way of enhancing QOL in patients with cancer and their families, and with regard to the context of each country, focusing on each area of practical guide, reviewing the status and available facilities, and learning from the experiences of other countries should be considered to achieve this goal.
\end{abstract}

Keywords: Palliative Care, Cancer, Health Policy, Content Analysis, United Kingdom, Malaysia, South Africa

\section{Context}

One of the problems of health systems all around the world is the increase in cancer load and its incidence rate, which is a serious threat to people's health $(1,2)$. Cancer is one of the major causes of mortality around the world (2-4). According to the World Health Organization (WHO), the cancer incidence rate is expected to increases 10 to 15 million new cases from 2000 to $2020(1,2)$. More than $90 \%$ of patients with fatal diseases including cancer have the dream of a peaceful death in an environment similar to their home. However, even in developed countries, only $20 \%$ to $30 \%$ of patients die at home, and according to Hig- ginson et al., it is estimated that by 2030, this amount will decrease to $10 \%$ (5). Many patients with cancer are admitted to hospitals to receive specialty care, and after receiving specialized and costly care, pass away without obtaining the desirable results, after experiencing a lot of pain. But, unfortunately, for most patients with cancer, death is inevitable in many cases despite applying advanced therapies and modern technologies for treating these diseases. Therefore, today, the main approach to taking care of these patients is to provide supportive and palliative care (6).

Palliative care has rapidly expanded in the United Kingdom (UK) since the late 1960s (7). In May 2005, the World Health Assembly mandated that all countries design and 
implement national cancer control programs. Accordingly, cancer support and palliative care are considered one of the 6 principles of cancer control programs in every country (8). The WHO recommended to all countries to prioritize these care services in their public health programs (9). Moreover, this organization believes that countries should have appropriate policies and a systematic framework for implementing these services in their health systems based on the available resources (10). According to the estimations made by the WHO, about $80 \%$ of those in need of care need only primary and non-specialized care, and only $20 \%$ of them need specialized care (11).

Palliative and supportive care are provided with regard to the specific condition of the patient, increasing QOL in dying patients with a comprehensive, patient-oriented, multidimensional, and humanistic approach, a concept that has mostly been ignored in providing health services $(12,13)$. The results of a study in 2007 showed that patients, who were provided with care at supportive and palliative care centers, lived 29 days longer than other similar patients (14). On the other hand, researchers also pointed out that supportive and palliative care can reduce the cost of treatment and health care (15-17). While many high-income countries have developed and implemented national policies to provide cancer supportive and palliative care (1820), many middle and lower-income countries still have no policy and plan at local and national levels despite the high burden of the disease (21). In 2004, the first international resolution was issued in the field of palliative care (WHA 67.19)(22).

The member states of the WHO demanded evidencebased tools to integrate palliative care into national health systems. For this purpose, the WHO's practical guideline was developed. This guideline explains how to plan and implement palliative care services at the national or international level through a step-by-step approach for low and middle-income countries. The chapters of this guideline include stewardship/policy actions, workforce, health care financing, service delivery, information and research, and access to medicines (22). In all countries, the care delivery approach is an important issue, and policymakers and health care decision-makers are trying to provide the highest quality care as one of the basic priorities of each country's health system, depending on the available resources (23). The provision of these services requires integrating and merging these services with the existing infrastructure of the health system, as well as considering the financial and human resources in the service delivery structure (24).

Many studies show that palliative care policies and the integration of these services in each country's health system can bring about benefits such as reducing undesired hospitalization, improving the quality of life (QOL), increasing the rate of survival, and reducing the economic burden of cancer on the shoulders of the patients' families and the health system (25-28). Despite many international recommendations around providing palliative care services from the very beginning of the disease and the integration of these services with the health system of each country, there are still many obstacles to achieve this important goal (29). Although the integration of palliative care in the early stages of cancer is routinely a part of the standard procedure in many countries such as Britain, in many developing countries such as Iran, palliative care services are in the early stages and their referral systems are very different from the ones in western countries $(27,30)$. In Iran, palliative care is a new concept, and there is no codified policy to provide such specialized services according to the demands, and there are only a few centers providing these services (31).

Palliative care is provided sporadically and is not efficiently protected by the health system, and the patients usually do not receive the necessary care. The existence of organized care programs and the integration of these services into the health system of the country are considered unmet needs (32). Since the application of an appropriate model in each care system depends on the health status and with regard to the economic situation, as well as the cultural and social status of the country, it is not possible to mention a set of fixed and pre-arranged goals for palliative care systems in the world (31). Therefore, the best choice can be made based on successful global experiences, studying the needs, considering the specific conditions of the country and, consequently, the policies of the health system of the society. Health policymakers play a significant role in the realization of this important goal (33). This study was conducted with the aim of comparing the policies and the strategies related to cancer supportive and palliative care in the selected countries, using the WHO practical guideline in order to assess the advantages, weaknesses, and limitations of these plans.

\subsection{Conceptual Framework}

The present study is based on the conceptual framework of "The World Health Organization Guide" with the approach of integrating palliative care in the health system (2014). This guide includes 6 policy orientations (development planning strategies), health system funding (development costs), service providers (hospitals, home care, etc.), human resources development (training programs), access to medicines (the rules and the access to medicines, especially opiates), and finally, information and research (evaluating information systems, multidisciplinary studies). At the stage of integration into the 
health system, each orientation has been classified into basic, moderate, and advanced levels (22). Palliative care program development has been subjected to many changes internationally; it is correlated with Human Development Index levels. Without policy support for palliative care and funding mechanisms, the development will be limited to what has been achieved by the pioneers' devotion to building hospices and palliative care service centers in their communities (34). The public health model for palliative care development is shown in Figure 1.

\section{Evidence Acquisition}

This study is a comparative study carried out to analyze the policies of cancer supportive and palliative care in various countries around the world. The studied countries were purposefully selected based on the reports of the economist intelligence unit, which studies the status of palliative care in 80 countries around the world, and classified as the countries by taking into account 20 quantitative and qualitative indicators in 5 classes, including healthcare and palliative care environment, care affordability, human resources, care quality, and society engagement. Accordingly, based on the availability of information and the existence of government services for examining the pattern of palliative care services, the selected countries are as follow: the UK from the group $4 \mathrm{~b}$ with an approach to integrating services; Malaysia from the group 4 a with generalized palliative care provision in some areas of the country; and South Africa from the group 4a with isolated palliative care provision in some areas. On the other hand, each of the studied countries is located in one of the 6 regions of the WHO. The UK is considered a developed and advanced country, Malaysia as a developing and pioneer country in Asia, and South Africa as a developing and pioneer country in Africa.

The data were collected through reviewing scientific and administrative documents, WHO website and reports, government websites (UK, Malaysia, and South-Africa), and other authoritative websites. The search was done through texts in English and the databases, including Science Direct, Scopus, and PubMed between 2000 and December 2018. In order to review the content of the policies and the strategies related to cancer supportive and palliative care, the WHO guideline is used, which is based on the integration of palliative care into the health system and includes stewardship/policy actions, workforce, health care financing, service delivery, information and research, and access to medicines (22) compared in the selected countries. The contents of the documents are analyzed based on the 5 chapters of this guideline, which are presented in Table 1.
After reviewing the content of palliative care in the selected countries, the data were extracted. First, the same data were removed and, then, the themes were identified and grouped according to the WHO framework. To ensure the validity and reliability of the data, 5 people were approved for their palliative care. Two authors (MA and SV) independently searched and selected the relevant documents. Policy document content was reviewed by 3 authors (SV, HR, and MA). Disagreement concerning the content of documents was resolved through discussion. Additionally, the key health indicators were investigated in the field related to the study as shown in Table 2 . We used a strategy search according to Medical Subject Headings terms. In this study, the following keywords were used: (“cancer" OR "cancer patients:) AND ("palliative care" OR "supportive care") AND ("policies" OR "programs" OR "strategies")AND ("UK" OR "Malaysia" OR “South Africa”). The data were analyzed by content analysis approach, using MAXQDA software version 11. After reviewing the content of palliative care in the selected countries, the data were extracted. First, the same data were removed and, then, the themes were identified and grouped according to the WHO framework. To ensure the validity and reliability of the data, 5 experts were approved for their palliative care.

\section{Results}

\subsection{The Ranking of Countries in Palliative Care Services}

In 2011, a report was issued by the International Observatory on End-of-Life Care and 234 countries were assessed and categorized into 4 groups regarding the development of palliative care services and based on indicators such as HDI, GDP, population size and raw mortality rate, the level of palliative care coverage, the type of the existing structure and the number of the levels of supportive and palliative care services, the level of the community's awareness of palliative care, and the amount of informing the public. According to this categorization, the studied countries belong to the fourth group, which includes the two subgroups of $a$ and $b$ (35). Table 3 shows the categories of the selected countries based on the development of palliative care.

The status of the selected countries mentioned in palliative care service of these countries is among the leading countries regarding the development of palliative care services; their support and palliative care systems possess some qualifications, such as palliative care integration approach, sufficient capacity to provide services in some parts of the country, the existence of a wide range of the types of palliative services and service providers, wide public awareness regarding care services, the existence of 


\section{Policy}

nalliative care part of national health plan, policies, related regulations

- Funding/service delivery models support palliative care delivery

Essential medicines

(Policy makers, regulators, WHO, NGOs)

Medicine availability

- Opioids, essential medicines

Importation quota

- Cost

- Prescribing

Distribution

Dispensing

Administration

(Pharmacists, drug regulators, law enforcement agents)

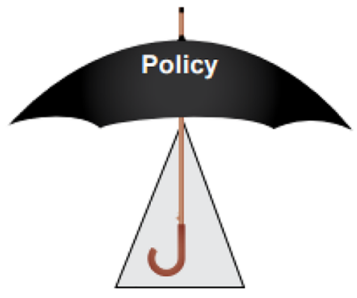

Education

- Media and public advocacy

- Curricula, courses professionals, trainees

- Expert training

- Family caregiver training and support

(Media and public healthcare providers and trainees, palliative care experts, family caregivers)

\section{Implementation}

- Opinion leaders

1 Trainer manpower

I Strategic and business plans resources, infrastructure

- Standards, guidelines measures

(Community and clinical leaders, administrators)

Stjernsward et al. $2007^{33}$. Used with permission.

Figure 1. Public health model for palliative care development, (WHO, 2014)

Table 2. Comparison of Health Performance Indicators in Selected Countries (2014 - 2015)

\begin{tabular}{|c|c|c|c|c|}
\hline Indicator & UK & Malaysia & South Africa & Source \\
\hline Population, 2018 & $66,573,504$ & $32,042,458$ & $57,398,421$ & WB \\
\hline Urban population, $\%$ & 80.6 & 75.37 & 65.295 & WB \\
\hline Population growth rate & 0.59 & 1.5 & 1.6 & WB \\
\hline Population 0 to 15 years, $\%$ & 17.619 & 24.621 & 29.178 & WB \\
\hline HDI, 2018 & Rank 14; 0,922 & Rank 57; 0,802 & Rank 113; 0,699 & UNDP \\
\hline GDP & $2,650,850.18$ & $296,535.93$ & $295,456.19$ & WB \\
\hline GNI & 42370 & 9860 & 5480 & WB \\
\hline Per capita expenditure on health & 4355.86 & 385.62 & 470.80 & WB \\
\hline Life expectancy & 80.956 & 75.3 & 62.774 & WB \\
\hline Cancer mortality & 166135 & 21500 & 41300 & WHO \\
\hline The mortality rate for children under 5 years in 1000 births & 4.3 & 8.3 & 43.3 & WB \\
\hline Maternal mortality in 1000 live births & 9 & 40 & 138 & WB \\
\hline WHO region & Europe & Western Pacific & Africa & WHO \\
\hline Income level classification of WB & High & Upper-middle income & Upper-middle income & WB \\
\hline Health Expenditure, \% GDP, 2015 & 9.88 & 4.00 & 8.20 & WHO \\
\hline
\end{tabular}

assessable integration and merging with health care systems' services, the establishment of special training cen- ters, large-scale academic communication, performance of applied studies, and the formation of national associa- 
Table 3. The Categories of the Selected Countries Based on the Development of Palliative Care

\begin{tabular}{cc}
\hline Group & Countries \\
\hline Group 4: Approaching integration & \\
4a-Preliminary integration & Malaysia; South Africa \\
4b-Advanced integration & UK \\
\hline
\end{tabular}

tions $(35,36)$.

\subsection{Epidemiological Overview}

UK: The UK is a high-income country located in Europe (37). In 2016, 166135 deaths caused by cancer were reported in this country. In 2014, 163200 individuals died, 86300 of whom were males and 76900 of whom were females. Figure $2 \mathrm{~A}$ shows the cancer mortality rate in both genders (38-40). In the UK, cancer accounted for more than 1 out of every 4 deaths (28\%) in 2016. Nearly half of all cancer deaths have been reported to be associated with lung, bowel, breast, or prostate. In 2018, the UK had a cancer rate of 31902 cases per 100000 people (41). More than 360 000 new cases of cancer are recorded annually in the UK. In 2015, the cancer rate was 183000 new cases in men and 177000 in women per year. Every 2 minutes, 1 cancer diagnosis is recorded in this country. The incidence rate of all types of cancers in the UK will rise by $2 \%$ from 2014 to 2035 , reaching a number of 742 new cases per 100000 by 2035. Compared with the European Union, the cancer incidence rate in the UK is lower in men and higher in women. The most common type of cancer in the UK is breast cancer in females and prostate cancer in males (38-40).

Malaysia: Malaysia is a country with an above-average income located in the western pacific region (42). In 2014, 21500 cancer deaths have been reported in this country, 11200 of which belonged to males and 10300 of which belonged to females. Figure $2 \mathrm{~B}$ shows the trend of agerelated cancer mortality in men and women (39). In 2018, 43837 new cancer cases and 26395 cancer deaths were estimated in Malaysia (43). Contagious diseases are currently the leading cause of mortality and illness in this country (44). The most common type of cancer in Malaysia is breast cancer in females and lung cancer in males (39).

South Africa: South Africa is a country with aboveaverage income located in the Africa region (45). In 2014, 41300 cancer deaths have been reported in the country, 20 700 of which belonged to males and 20600 of which belonged to females. Figure $2 \mathrm{C}$ shows age-related cancer mortality in men and women (40). The most common type of cancer is breast cancer in females and prostate cancer in men. The cancer mortality rate in these countries is about $5 \%$, which is much lower compared with European coun- tries (20\%) (40). Cancer is not among the 10 leading causes of death in South Africa. According to the mortality rate data, the estimated need for palliative care in this country accounts for only $0.52 \%$ of the population's need (46).

\subsection{Stewardship/Policy Actions}

In the UK, health management is done by the local authorities of each region, and the health system is responsible for developing protocols and palliative care guidelines (47). In Malaysia, public health services are also managed in an organized way, through central, provincial, and regional departments, under the administration of the Ministry of Health $(48,49)$. In South Africa, health centers are run by provincial health departments, and provincial offices are direct employers of health workers, while the Ministry of Health is responsible for policy development and coordination $(11,46)$.

\subsection{Workforce}

There are 6000 to 7000 palliative care professionals (around 5000 nurses, 750 physicians, and 70000 social volunteers) employed in the UK. There are academic and higher education palliative care centers available in the country $(50,51)$. In 2016 , there are 18 trained professionals in the field of palliative care working in Malaysia (52). From 2003 to 2004,842 recruited employees had been working in the field of palliative care for around 125780 hours per month in South Africa. On the other hand, the volunteer workforce consisted of 1978 people working a total of 25 806 hours per month within this period (46).

\subsection{Health Care Financing}

In the UK, $83 \%$ of hospital consultation costs, $59 \%$ of home care costs, $30 \%$ of hospitalization costs, and $23 \%$ of day clinics costs are paid by the government, and the rest is financed by a combined budget from both public and private sectors, and the government is responsible for the majority of financing (53). In Malaysia, only patients meeting the criteria set by the Ministry of Health receive care through federal funding. Mostly, this financial burden is placed on charity (54). In South Africa, along with service provision centers, there are private hospitals and clinics for those, who have health insurance coverage or can pay out of pocket for healthcare (46).

\subsection{Service Delivery}

In the UK, palliative care is integrated into the health system (55), while in South Africa, palliative care is provided in an isolated form in some areas. The coverage of palliative care is not centralized; in some areas, comprehensive care is provided at an appropriate level, while in 
other parts, even basic level care is not available $(46,56)$. In Malaysia, these services are provided only in some areas, but in a generalized and comprehensive form (22).

\subsection{Information and Research}

In 2001, the quality improvement Department for Cancer Services in the UK has regulated the standards of cancer service (57). In addition, the government commitments to the high quality of end-of-life care were developed in the Department of Health and Social Care (58). In 2016, Hopis Malaysia published a report titled Palliative Care Need Assessment (59). In 2005, South Africa formulated a standard manual for healthcare in cooperation with the Council for Health Services Accreditation of South Africa in order to evaluate the quality of services provided by the charity sector, whose third edition is currently in use (46).

Key health indicators in the field related to the study, as well as the policies and the plans for cancer supportive and palliative care in the selected countries based on the WHO guidelines in the fields of stewardship/policy actions, workforce, health care financing, service delivery, and information and research, are presented in Tables 1 and 2.

\section{Discussion}

This article compares the policies and the strategies for cancer supportive and palliative care in the UK, Malaysia, and South Africa. According to a report by the British Parliamentary and Health Service (2015), the causes of failure in palliative care provision in the UK were as follow: Weak symptom control, weak planning, communication, not addressing the needs of dying patients, insufficient out-ofhour services, ill-timed diagnoses, and treatment referrals (60).

National policies play an important role in spreading access to palliative care (22). One of the factors that distinguish the policies of different countries in supportive and palliative care provision is the existence and efficiency of a state strategy for national palliative care (55). In the $\mathrm{UK}$, there is a comprehensive strategy for the enhancement and development of national palliative care. The vision and targets are clarified, and an action plan is defined along with powerful mechanisms in order to achieve these targets. Besides, the strategies are clearly determined by the central government and are regularly assessed and updated, and local governments should follow them. In fact, the policy implementation process has is up-down $(36,50)$. However, in Malaysia and South Africa, despite the fact that there is a governmental strategy and a broad vision of the development and promotion of national palliative care, the general and the specific goals are not defined and there are limited mechanisms to achieve goals $(46,56)$. In these countries, unlike the UK, the local states are not obliged to follow national strategies. In other words, these strategies are only prescriptive in nature $(36,61)$. In these countries, the Ministry of Health is responsible for the stewardship and the policy actions of palliative care, and regional departments are responsible for implementing these policies $(50,62)$. One of the advantages of South Africa is its major role in global issues and a palliative care statement during the African Union Summit in 2013 issued by the Minister of Health (36). In 2016, a palliative care policy framework was also approved. The UK owns the highest quality of death as a result of inclusive national policies, the broad integration of palliative care into national healthcare services, and the powerful hospice movement. It also has the highest score for care quality. Generally, income level is a good indicator of palliative care accessibility and quality: rich countries such as the UK are placed high in the ranking of palliative care (55).

One of the success factors in achieving palliative care goals is the deployment of professional and specialized personnel (36). There are adequate professional palliative care experts in the UK, which are approved by national professional boards. Volunteers must also attend a training course. The UK is the first country, in which palliative care has emerged (51). It also has the best children palliative care services (63). As in the UK, there is professional palliative care staff in Malaysia and South Africa. However, there is a shortage of doctors, nurses, and other support staff( 49 , 64). Unlike the UK, in this country, specialized palliative care education does not generally need to be approved by national professional boards (36). Although South Africa is not among the top countries in the human resources ranking (ranked 59th), it is, in many cases, a leading force in training and educating the workforce. The first MSc degree in the field of palliative care was presented at the University of Cape Town, South Africa (65). Another advantage of the palliative care plan in this country is the education of family physicians with the aim of integrating palliative care into the healthcare system. Among the successful programs in the UK, which other countries can adopt, lunching the National End-of-Life Care Intelligence Network in April 2013 and developing Background Electronic Palliative Care Coordination Systems within the palliative care system can be mentioned (66).

In order to increase access to palliative care, government funding is essential. In some countries, despite the fact that government funding is allocated to this type of care, either it is difficult to access it or it is poorly monitored $(22,36)$. In many countries, including the UK, providing palliative care is possible through charity (55). In the UK, government subsidies or public programs exist 

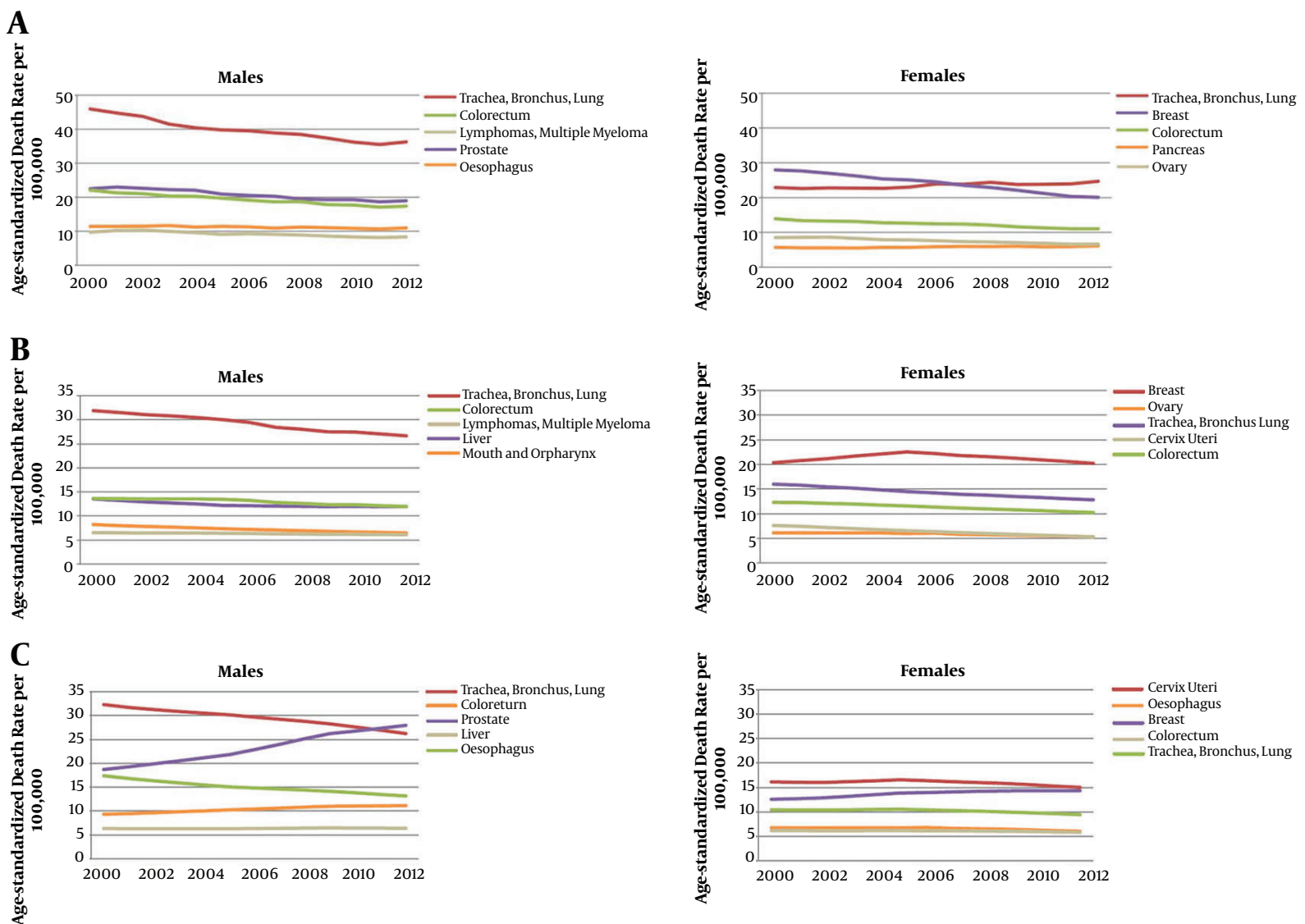

Figure 2. Age-standardized cancer mortality trends in; A, United Kingdom; B, Malaysia; and C, South Africa between 2000 and 2012.

for individuals to increase the accessibility to palliative care. There are clear qualification criteria and simple procedures for using funds. There are instructions for accessing these funds. The effectiveness of this plan is examined on a regular basis (36). In Malaysia and South Africa, as in the UK, there are government subsidies or appropriate plans for people, who have access to palliative care $(36,48)$. Qualification criteria are also clear, but unlike the UK, access to budgets and programs is difficult and the effectiveness of programs is not monitored. Subsidies are needed for palliative care services in order to make the treatments more affordable. These aids are provided in the form of national insurances, pension programs, and charity funds, the same as in the UK(55).

A large number of patients die every year in hospitals globally, but many of them spend their final days at home or in hospices (22). England is one of the countries that is making changes in order to increase the quality of care received by patients and help reduce the costs of the National Health Service in the country (67). While countries need to take efforts for increasing palliative care accessibility and make the services affordable, the quality of care should also be taken into account. It should be ensured that painkillers, such as opioids, are easily available and managed properly $(22,36)$. Opioid painkillers are freely available in the UK. However, in South Africa and Malaysia, these drugs are always available or can be accessed only through specific laws, bureaucratic procedures, and prejudices $(36,62)$. South Africa has better access to medications than many African countries do (65). One of the South African national policies for palliative care $(2017$ - 2022) is the correct and stable access to appropriate medicines and related supplies to provide palliative care (68).

When the end-of-life comes, community engagement becomes important. When communities, volunteers, and families accept more responsibility, emergency admissions and hospital costs will be decreased. For policymakers, the question is how to increase motivations and develop support systems for further encouraging the community. In today's world, people find it hard to discuss top- 
ics around death. So, it is of importance that social groups increase public awareness of palliative care. Another advantage of palliative care in the UK is that it has the second place in terms of public awareness on this field, of which people have a strong perception. Information on palliative care can easily be found through public portals and communities (69). But, in Malaysia and South Africa, people have an average perception and knowledge about palliative care. Besides, the information available in this regard on public portals and communities is not broad $(36,48,49)$. The palliative care resolution issued by the World Health Assembly has created a strong motive for all countries to formulate palliative care policies, and in most countries, there is a big deal of effort made to ensure that all citizens access palliative care. However, in many developing countries there is still little or even no access to palliative care (19).

In Iran, due to the high rates of cancer-related mortality and the high cost of treating this disease (70), the health system requires to design of a purposeful program that will prioritize providing palliative care services to patients with cancer. By examining and analyzing palliative care policies in countries like the UK, Malaysia, and South Africa, all of which are pioneers in developing palliative care services and selected from 3 different continents, lessons can be learned from the challenges, weak points, and strengths of their policies and plans. They can be used as models for countries like Iran, which is at the beginning of its path. Although different models and policies have been presented for the provision of palliative care services in patients with cancer, in integration with the health system in different countries, selecting and implementing them requires attention and considering the specific conditions of each society and, consequently, the policies of the health system in that country and, ultimately, informed decision-making by health-care policymakers.

The present study had limitations, some of which can be mentioned here. It was not possible to access to all the data of the target countries. Some programs may be inaccessible or confidential; nevertheless, the authors of this study tried to review all the documents. The diversity of health structures and documents in the selected countries has led to lots of differences in the implementation of various programs, posing challenges in decision making around choosing the best policies.

\subsection{Conclusions}

Countries should consider palliative care as one of the top priorities of the health system and a method for improving QOL in patients with cancer and their relatives due to the high prevalence of chronic and incurable diseases such as cancer, the increased aging population, limited intensive care beds, the shortage of equipment, financial and human resources in medical centers, and the importance of palliative care as a missing link in the cycle of healthcare. Although most countries in the world still have a long way to reach the desired level in providing support and palliative care, they can accomplish this goal by taking into account the conditions of each country, focusing on each area of practical guideline, examining the situation and the facilities available, and learning from the experiences of other countries.

\section{Acknowledgments}

This article was part of a PhD thesis supported by the School of Iran University of Medical Sciences (IUMS/SHMIS_1394/9221557202).

\section{Footnotes}

Authors' Contribution: Study design: Mahtab Alikhani and Soudabeh Vatankhah. Data collection: Mahtab Alikhani, Hasan Abolghasem Gorji, and Hamid Ravaghi. Data analysis: Mahtab Alikhani and Soudabeh Vatankhah. Final revision and grammar editing: Mahtab Alikhani, Soudabeh Vatankhah, and Hasan Abolghasem Gorji. All authors read and approved the final manuscript.

Conflict of Interests: The authors declared no conflict of interest.

Funding/Support: This research was supported by the Iran University of Medical Sciences.

\section{References}

1. Sturmberg JP, O'Halloran DM, Martin CM. Understanding health system reform - a complex adaptive systems perspective. J Eval Clin Pract. 2012;18(1):202-8. doi: 10.1111/j.1365-2753.2011.01792.x. [PubMed: 22221420].

2. Bray F, Ferlay J, Soerjomataram I, Siegel RL, Torre LA, Jemal A. Global cancer statistics 2018: GLOBOCAN estimates of incidence and mortality worldwide for 36 cancers in 185 countries. CA Cancer J Clin. 2018;68(6):394-424. doi: 10.3322/caac.21492. [PubMed: 30207593].

3. Matsushita T, Matsushima E, Maruyama M. Psychological state, quality of life, and coping style in patients with digestive cancer. Gen Hosp Psychiatry. 2005;27(2):125-32. doi: 10.1016/j.genhosppsych.2004.10.006. [PubMed: 15763124].

4. Mehrtak M, Vatankhah S, Delgoshaei B, Gholipour A. Succession planning in the Iranian health system: A case study of the Ministry of Health and Medical Education. Glob J Health Sci. 2014;6(5):174-82. doi: 10.5539/gjhs.v6n5p174. [PubMed: 25168998]. [PubMed Central: PMC4825495].

5. Manfuku M, Nishigami T, Mibu A, Tanaka K, Kitagaki K, Sumiyoshi K. Comparison of central sensitization-related symptoms and healthrelated quality of life between breast cancer survivors with and without chronic pain and healthy controls. Breast Cancer. 2019;26(6):75865. doi: 10.1007/s12282-019-00979-y. [PubMed: 31127501]. 
6. Higginson IJ, Sen-Gupta GJ. Place of care in advanced cancer: A qualitative systematic literature review of patient preferences. J Palliat Med. 2000;3(3):287-300. doi: 10.1089/jpm.2000.3.287. [PubMed: 15859670].

7. Azami-Aghdash S, Ghojazadeh M, Naghavi-Behzad M, Imani S, Aghaei MH. Perspectives of cardiac care unit nursing staff about developing hospice services in Iran for terminally ill cardiovascular patients: A qualitative study. Indian J Palliat Care. 2015;21(1):56-60. doi: 10.4103/0973-1075.150185. [PubMed: 25709187]. [PubMed Central: PMC4332129].

8. Clark D. From margins to centre: A review of the history of palliative care in cancer. Lancet Oncol. 2007;8(5):430-8. doi: 10.1016/S14702045(07)70138-9. [PubMed: 17466900].

9. [No Authors Listed]. National cancer control programmes: Policies and managerial guidelines. 2nd ed. Geneva: WHO; 2002. p. 83-92.

10. De Lima L, Radbruch L. Palliative care in the global health agenda. J Pain Palliat Care Pharmacother. 2014;28(4):384-9. doi: 10.3109/15360288.2014.972487. [PubMed: 25338105].

11. Lankester T. Restoring hope: Decent care in the midst of HIV/AIDS. In: Karpf T, Ferguson JT, Swift R, Lazarus JV, editors. Hiv Medicine. 9. London: Palgrave Macmillan; 2008. 27 p. doi: 10.1057/9780230595217.

12. Harding R, Powell RA, Downing J, Connor SR, Mwangi-Powell F, Defilippi K, et al. Generating an African palliative care evidence base: The context, need, challenges, and strategies. J Pain Symptom Manage. 2008;36(3):304-9. doi: 10.1016/j.jpainsymman.2008.04.008. [PubMed: 18722312].

13. Winzelberg GS, Patrick DL, Rhodes LA, Deyo RA. Opportunities and challenges to improving end-of-life care for seriously ill elderly patients: A qualitative study of generalist physicians. $J$ Palliat Med. 2005;8(2):291-9. doi:10.1089/jpm.2005.8.291. [PubMed: 15890040].

14. Lau BD, Aslakson RA, Wilson RF, Fawole OA, Apostol CC, Martinez $\mathrm{KA}$, et al. Methods for improving the quality of palliative care delivery: A systematic review. Am J Hosp Palliat Care. 2014;31(2):202-10. doi: 10.1177/1049909113482039. [PubMed: 23532404]. [PubMed Central: PMC4696032].

15. Kulkarni Vinaya RKRV. Comparative study of awareness of communication skills, palliative care treatment among m.B.B.S., nursing, and physiotherapy students. Int J Sci Res. 2017;6(7):3535. doi: 10.15373/22778179. [PubMed: 31069180]. [PubMed Central: PMC6502256].

16. Casarett DJ, Quill TE. "I'm not ready for hospice": Strategies for timely and effective hospice discussions. Ann Intern Med. 2007;146(6):443-9. doi: 10.7326/0003-4819-146-6-200703200-00011. [PubMed: 17371889].

17. Pyenson B, Connor S, Fitch K, Kinzbrunner B. Medicare cost in matched hospice and non-hospice cohorts. J Pain Symptom Manage. 2004;28(3):200-10. doi: 10.1016/j.jpainsymman.2004.05.003. [PubMed: 15336332].

18. Miller SC, Intrator O, Gozalo P, Roy J, Barber J, Mor V. Government expenditures at the end of life for short- and long-stay nursing home residents: differences by hospice enrollment status. J Am Geriatr Soc. 2004;52(8):1284-92. doi: 10.1111/j.1532-5415.2004.52357.x. [PubMed: 15271115].

19. Miller SC, Mor V, Wu N, Gozalo P, Lapane K. Does receipt of hospice care in nursing homes improve the management of pain at the end of life? J Am Geriatr Soc. 2002;50(3):507-15. doi: 10.1046/j.15325415.2002.50118.x. [PubMed: 11943048].

20. Mitchell S, Tan A, Moine S, Dale J, Murray SA. Primary palliative care needs urgent attention. BMJ. 2019;365:11827. doi: 10.1136/bmj.11827. [PubMed: 31000501].

21. Coast J. Strategies for the economic evaluation of end-of-life care: making a case for the capability approach. Expert Rev Pharmacoecon Outcomes Res. 2014;14(4):473-82. doi: 10.1586/14737167.2014.914436. [PubMed: 24784902].

22. Bastani P, Samadbeik M, Dinarvand R, Kashefian-Naeeini S, Vatankhah S. Qualitative analysis of national documents on health care services and pharmaceuticals" purchasing challenges: Evidence from
Iran. BMC Health Serv Res. 2018;18(1):410. doi: 10.1186/s12913-018-3261-0. [PubMed: 29871679]. [PubMed Central: PMC5989418].

23. Azami-Aghdash S, Ghojazadeh M, Aghaei MH, Naghavi-Behzad M, Asgarlo Z. Perspective of patients, patients' families, and healthcare providers towards designing and delivering hospice care services in a middle income Country. Indian J Palliat Care. 2015;21(3):341-8. doi: 10.4103/0973-1075.164898. [PubMed: 26600704]. [PubMed Central: PMC4617043].

24. [No Authors Listed]. Planning and implementing palliative care services: A guide for programme managers. Geneva: World Health organization; 2016. p. 17-69.

25. Mainz J, Bartels PD. Nationwide quality improvement-how are we doing and what can we do? Int J Qual Health Care. 2006;18(2):79-80. doi: 10.1093/intqhc/mzi099. [PubMed: 16434508].

26. Stjernsward J, Foley KM, Ferris FD. The public health strategy for palliative care. J Pain Symptom Manage. 2007;33(5):486-93. doi: 10.1016/j.jpainsymman.2007.02.016. [PubMed: 17482035].

27. Parikh RB, Kirch RA, Smith TJ, Temel JS. Early specialty palliative care-translating data in oncology into practice. $N$ Engl J Med. 2013;369(24):2347-51. doi: 10.1056/NEJMsb1305469. [PubMed: 24328469]. [PubMed Central: PMC3991113].

28. Morrison RS, Dietrich J, Ladwig S, Quill T, Sacco J, Tangeman J, et al. Palliative care consultation teams cut hospital costs for medicaid beneficiaries. Health Aff (Millwood). 2011;30(3):454-63. doi: 10.1377/hlthaff.2010.0929. [PubMed: 21383364].

29. Baek YJ, Shin DW, Choi JY, Kang J, Mo HN, Kim YH, et al. Late referral to palliative care services in Korea. J Pain Symptom Manage. 2011;41(4):692-9. doi: 10.1016/j.jpainsymman.2010.06.019. [PubMed: 21232909].

30. Gaertner J, Siemens W, Antes G, Meerpohl JJ, Xander C, Schwarzer G, et al. Specialist palliative care services for adults with advanced, incurable illness in hospital, hospice, or community settings-protocol for a systematic review. Syst Rev. 2015;4:123. doi: 10.1186/s13643-015-0121-4. [PubMed: 26407847]. [PubMed Central: PMC4583160].

31. Von Roenn JH, Voltz R, Serrie A. Barriers and approaches to the successful integration of palliative care and oncology practice. J Natl Compr Canc Netw. 2013;11 Suppl 1:S11-6. doi: 10.6004/jnccn.2013.0209. [PubMed: 23520181]

32. Gu X, Cheng W, Chen M, Liu M, Zhang Z. Timing of referral to inpatient palliative care services for advanced cancer patients and earlier referral predictors in mainland China. Palliat Support Care. 2016;14(5):5039. doi: 10.1017/S1478951515001212. [PubMed: 26481125].

33. Rassouli M, Sajjadi M. Palliative care in Iran: Moving toward the development of palliative care for cancer. Am J Hosp Palliat Care. 2016;33(3):240-4. doi: 10.1177/1049909114561856. [PubMed: 25492970].

34. Rassouli M, Sajjadi M. Cancer care in countries in transition: The Islamic Republic of Iran. Cancer care in countries and societies in transition. New York: Springer; 2016. p. 317-36. doi: 10.1007/978-3-319-22912$6 \_20$.

35. Foster TL, Lafond DA, Reggio C, Hinds PS. Pediatric palliative care in childhood cancer nursing: From diagnosis to cure or end of life. Semin Oncol Nurs. 2010;26(4):205-21. doi: 10.1016/j.soncn.2010.08.003. [PubMed: 20971402].

36. Connor SR, Sepulveda Bermedo MC. Global atlas of palliative care at the end oflife. New York: Springer, Cham;2018. doi:10.1007/978-3-319-317380 4-1.

37. Wright M, Wood J, Lynch T, Clark D. Mapping levels of palliative care development: A global view. J Pain Symptom Manage. 2008;35(5):46985. doi: 10.1016/j.jpainsymman.2007.06.006. [PubMed: 18243637].

38. Curtis H, Motova A, Quintana MM, Witteveen A. A text-book case study: Economic analysis informing governance and management of scallop fishing in the UK. International Institute of Fisheries Economics \& Trade; 2018.

39. World Health Organization. Cancer country profiles, United Kingdom. 2014. 
40. World Health Organization. Cancer country profiles, Malaysia. 2014. 41. World Health Organization. Cancer country profiles, South Africa. 2014.

42. Torre LA, Bray F, Siegel RL, Ferlay J, Lortet-Tieulent J, Jemal A. Global cancer statistics, 2012. CA Cancer J Clin. 2015;65(2):87-108. doi: 10.3322/caac.21262. [PubMed: 25651787].

43. Lim YW, Shafie AA, Chua GN, Ahmad Hassali MA. Determination of cost-effectiveness threshold for health care interventions in Malaysia. Value Health. 2017;20(8):1131-8. doi: 10.1016/j.jval.2017.04.002. [PubMed: 28964445].

44. Alaini R, Rajikan R, Elias SM. Diet optimization using linear programming to develop low cost cancer prevention food plan for selected adults in Kuala Lumpur, Malaysia. BMC Public Health. 2019;19(Suppl 4):546. doi: 10.1186/s12889-019-6872-4. [PubMed: 31196148]. [PubMed Central: PMC6565536].

45. Myint CY, Pavlova M, Thein KN, Groot W. A systematic review of the health-financing mechanisms in the Association of Southeast Asian Nations countries and the People's Republic of China: Lessons for the move towards universal health coverage. PLoS One. 2019;14(6). e0217278. doi: 10.1371/journal.pone.0217278. [PubMed: 31199815]. [PubMed Central: PMC6568396].

46. Leibbrandt M, Finn A, Woolard I. Describing and decomposing post-apartheid income inequality in South Africa. Dev South Africa. 2012;29(1):19-34. doi: 10.1080/0376835x.2012.645639.

47. Drenth C, Sithole Z, Pudule E, Wust S, GunnClark N, Gwyther L. Palliative care in South Africa. J Pain Symptom Manage. 2018;55(2S):S170-7. doi: 10.1016/j.jpainsymman.2017.04.024. [PubMed: 28803085].

48. Evans N, Menaca A, Andrew EV, Koffman J, Harding R, Higginson IJ, et al. Appraisal of literature reviews on end-of-life care for minority ethnic groups in the UK and a critical comparison with policy recommendations from the UK end-of-life care strategy. BMC Health Serv Res. 2011;11:141. doi: 10.1186/1472-6963-11-141. [PubMed: 21635738]. [PubMed Central: PMC3146404].

49. Lau C, Pickersgill M. Integrating, advocating and augmenting palliative care in Malaysia: A qualitative examination of the barriers faced and negotiated by Malaysian palliative care nongovermental organisations. J Glob Health Rep. 2019;3. e2019003. doi: 10.29392/joghr.3.e2019003. [PubMed: 31363500]. [PubMed Central: PMC6667336].

50. Leong RL. Palliative care in Malaysia: A decade of progress and going strong. J Pain Palliat Care Pharmacother. 2003;17(3-4):77-85. discussion 87-9. [PubMed: 15022953 ].

51. Craigs CL, West RM, Hurlow A, Bennett MI, Ziegler LE. Access to hospital and community palliative care for patients with advanced cancer: A longitudinal population analysis. PLoS One. 2018;13(8). e0200071. doi: 10.1371/journal.pone.0200071. [PubMed: 30089106]. [PubMed Central: PMC6082504].

52. ElMokhallalati Y, Woodhouse N, Farragher T, Bennett MI. Specialist palliative care support is associated with improved pain relief at home during the last 3 months of life in patients with advanced disease: Analysis of 5-year data from the national survey of bereaved people (VOICES). BMC Med. 2019;17(1):50. doi:10.1186/s12916-019-1287-8. [PubMed: 30898162]. [PubMed Central: PMC6429790]

53. Cheah CF, Winnie LHY, Merriman A, Mohd Naseri NI, Chew SWY. 1535PSarawak: Healthcare professionals' perception of palliative care at end of life. Annals of Oncology. 2018;29(suppl_8). doi: 10.1093/annonc/mdy295.024.

54. Ansari MM, Rassouli M, Akbari ME, Abbaszadeh A, Akbarisari A, Haghighat S. Process challenges in palliative care for cancer patients: A qualitative study. Middle East J Cancer. 2019;10(1):43-53.

55. Koh KC, Gupta ED, Poovaneswaran S, Then SL, Teo MJ, Gan TY, et al Concordance in the assessment of effectiveness of palliative care between patients and palliative care nurses in malaysia: A study with the palliative care outcome scale. Indian JPalliat Care. 2017;23(1):46-52. doi: 10.4103/0973-1075.197961. [PubMed: 28216862]. [PubMed Central: PMC5294437].

56. Nakanishi M, Nakashima T, Shindo Y, Miyamoto Y, Gove D, Radbruch L, et al. An evaluation of palliative care contents in national dementia strategies in reference to the European Association for Palliative Care white paper. Int Psychogeriatr. 2018;27(9):1551-61. doi: 10.1017/S1041610215000150. [PubMed: 25678323].

57. Rhee JY, Garralda E, Namisango E, Luyirika E, de Lima L, Powell RA et al. An analysis of palliative care development in Africa: A ranking based on region-specific macroindicators. JPain Symptom Manage. 2018;56(2):230-8. doi: 10.1016/j.jpainsymman.2018.05.005. [PubMed: 29772280].

58. Brown BB, Patel C, McInnes E, Mays N, Young J, Haines M. The effectiveness of clinical networks in improving quality of care and patient outcomes: A systematic review of quantitative and qualitative studies. BMC Health Serv Res. 2016;16:360. doi: 10.1186/s12913-016-1615-z. [PubMed: 27613378]. [PubMed Central: PMC5018194].

59. Jones L, Candy B, Davis S, Elliott M, Gola A, Harrington J, et al Development of a model for integrated care at the end of life in advanced dementia: A whole systems UK-wide approach. Palliat Med. 2016;30(3):279-95. doi: 10.1177/0269216315605447. [PubMed: 26354388]. [PubMed Central: PMC4766969].

60. Edib Z, Kumarasamy V, Binti Abdullah N, Rizal AM, Al-Dubai SA. Most prevalent unmet supportive care needs and quality of life of breast cancer patients in a tertiary hospital in Malaysia. Health Qual Life Outcomes. 2016;14:26. doi: 10.1186/s12955-016-0428-4. [PubMed: 26898558] [PubMed Central: PMC4762172].

61. Borgstrom E, Walter T. Choice and compassion at the end of life: A crit ical analysis of recent English policy discourse. Soc Sci Med. 2015;1367:99-105. doi: 10.1016/j.socscimed.2015.05.013. [PubMed: 25989003]

62. Jarrett J, Woodcock J, Griffiths UK, Chalabi Z, Edwards P, Roberts I, et al. Effect of increasing active travel in urban England and Wales on costs to the National Health Service. Lancet. 2012;379(9832):2198-205. doi: 10.1016/S0140-6736(12)60766-1. [PubMed: 22682466].

63. Harding R, Higginson IJ. Palliative care in sub-Saharan Africa. The Lancet. 2005;365(9475):1971-7. doi: 10.1016/s0140-6736(05)66666-4.

64. Stockley A, Forbes K. 161 Palliative care for young people with lifelimiting illness: What should we be teaching specialist palliative care trainees? BMJ Support Palliat Care. 2019;9(1). doi: 10.1136/bmjspcare2019-ASP.184.

65. Ens CD, Chochinov HM, Gwyther E, Moses S, Jackson C, Thompson G et al. Postgraduate palliative care education: Evaluation of a South African programme. S Afr Med J.2011;101(1):42-4. doi:10.7196/samj.4171. [PubMed: 21626981].

66. Mehta AK, Najjar S, May N, Shah B, Blackhall L. A needs assessment of palliative care education among the United States adult neurology residency programs. J Palliat Med. 2018;21(10):1448-57. doi: 10.1089/jpm.2018.0191. [PubMed: 30088969].

67. Allsop MJ, Kite S, McDermott S, Penn N, Millares-Martin P, Bennett MI. Electronic palliative care coordination systems: Devising and testing a methodology for evaluating documentation. Palliat Med 2017;31(5):475-82. doi: 10.1177/0269216316663881. [PubMed: 27507636]. [PubMed Central: PMC5405823].

68. Zele-Mqonci N. Assessment of quality of care provided to patients who died in the care of Tshwane District Hospital. Sout Africa: University of Cape Town; 2019.

69. Coovadia H, Jewkes R, Barron P, Sanders D, McIntyre D. The health and health system of South Africa: Historical roots of current public health challenges. Lancet. 2009;374(9692):817-34. doi: 10.1016/S01406736(09)60951-X. [PubMed: 19709728].

70. Seymour J. Looking back, looking forward: The evolution of palliative and end-of-life care in England. Mortality. 2012;17(1):1-17. doi: $10.1080 / 13576275.2012 .651843$. 
Table 1. Comparison of the Content Analysis of Cancer Palliative Care in the Selected Countries

\begin{tabular}{|c|c|c|c|}
\hline Component & UK & Malaysia & South Africa \\
\hline \multirow{10}{*}{ Stewardship/policy actions } & $\begin{array}{l}\text { The Ministry of Health is responsible for providing } \\
\text { palliative care protocols and guidelines. }\end{array}$ & $\begin{array}{l}\text { The Ministry of Health plans } \\
\text { public health and medical care } \\
\text { programs but has little legal } \\
\text { power in the private sector. }\end{array}$ & $\begin{array}{l}\text { Providing palliative care services } \\
\text { mainly through charity centers or } \\
\text { the National Palliative Care } \\
\text { Association }\end{array}$ \\
\hline & $\begin{array}{l}\text { 1991- The formation of the National Council for } \\
\text { Hospice and Palliative Care Services, renamed to } \\
\text { the National Council for Palliative Care in } 2004\end{array}$ & $\begin{array}{l}\text { Major palliative care services are } \\
\text { provided by the charity and } \\
\text { non-profit sectors. }\end{array}$ & $\begin{array}{l}2016 \text { - Approving a policy } \\
\text { framework for palliative care }\end{array}$ \\
\hline & $\begin{array}{l}\text { The responsibility of the health and its public } \\
\text { policies in the UK is given to the Parliament, the } \\
\text { Ministry of Health, and the National Health Service. }\end{array}$ & & \\
\hline & $\begin{array}{l}\text { 1970-The establishment of the National Hospice } \\
\text { Organization supervised by National Health Service }\end{array}$ & & \\
\hline & $\begin{array}{l}\text { 1995- The establishment of the first palliative care } \\
\text { unit at Queen Elizabeth Hospital }\end{array}$ & & \\
\hline & $\begin{array}{l}\text { 2004- Designing a national program for the } \\
\text { development of palliative care }\end{array}$ & & \\
\hline & $\begin{array}{l}\text { 2008- Developing end-of-life strategies and } \\
\text { launching a national strategy for children's } \\
\text { palliative care }\end{array}$ & & \\
\hline & $\begin{array}{l}\text { The UK Foreign Office has a legal duty to promote } \\
\text { comprehensive health services. }\end{array}$ & & \\
\hline & $\begin{array}{l}\text { Issuing an executive order by the government, on } \\
\text { the necessity of palliative care provision for any } \\
\text { life-limiting illness }\end{array}$ & & \\
\hline & $\begin{array}{l}\text { The integration of palliative care into the health } \\
\text { system }\end{array}$ & & \\
\hline \multirow{9}{*}{ Workforce } & The first country to have palliative care & $\begin{array}{l}\text { 2016- } 18 \text { trained palliative care } \\
\text { experts }\end{array}$ & $\begin{array}{l}\text { Offering palliative care education } \\
\text { at various levels, and by various } \\
\text { organizations such as the } \\
\text { University of Cape Town }\end{array}$ \\
\hline & Pioneer in the field of palliative medicine & $\begin{array}{l}\text { Developing an advanced Diploma } \\
\text { Program for nurses, } \\
\text { physiotherapists, and therapists }\end{array}$ & $\begin{array}{l}\text { Most hospices relying on } \\
\text { professional volunteers }\end{array}$ \\
\hline & $\begin{array}{l}6000-7000 \text { palliative care specialists, about } 5000 \\
\text { nurses, } 750 \text { physicians, and } 70000 \text { social } \\
\text { volunteers }\end{array}$ & $\begin{array}{l}\text { Training } 38 \text { nurses and federal } \\
\text { specialists }\end{array}$ & \\
\hline & $\begin{array}{l}\text { Palliative care academic and higher education } \\
\text { centers such as Cicely-Saunders Institute }\end{array}$ & $\begin{array}{l}\text { Major human resources } \\
\text { providing palliative care } \\
\text { consisting of voluntary activities }\end{array}$ & \\
\hline & $\begin{array}{l}\text { Holding virtual training courses and specialized } \\
\text { training in undergraduate and postgraduate } \\
\text { degrees }\end{array}$ & $\begin{array}{l}\text { Non-governmental organizations } \\
\text { such as the Hospis Malaysia and } \\
\text { the National Cancer Society } \\
\text { Malaysia are the main providers } \\
\text { of palliative care }\end{array}$ & \\
\hline & $\begin{array}{l}\text { Training physicians for specialized palliative care } \\
\text { in a 4-5-year course }\end{array}$ & & \\
\hline & Specialized pediatric palliative care & & \\
\hline & $\begin{array}{l}\text { More than } 220 \text { charitable organizations and } \\
\text { private institutions }\end{array}$ & $\begin{array}{l}\text { The health care system includes } \\
\text { government and private } \\
\text { financing }\end{array}$ & $\begin{array}{l}\text { Private hospitals and clinics } \\
\text { provide services, as well as } \\
\text { government centers. }\end{array}$ \\
\hline & Providing completely free palliative care services & $\begin{array}{l}\text { Patients meeting the criteria set } \\
\text { by the Ministry of Health receive } \\
\text { care through federal funding. }\end{array}$ & $\begin{array}{l}\text { Hospice centers are charitable } \\
\text { and non-governmental } \\
\text { organizations }\end{array}$ \\
\hline
\end{tabular}


Palliative care provision through the efforts of the voluntary sector
All palliative care services at home or private centers are provided by non-governmental organizations. Costs are paid by the family, grants, and the tax paid by NGOs.

palliative care burden mostly on the Charity sector

29 out of 99 public hospital provide palliative care services based on the Ministry of Health guidelines through federal funding.

End-of-Life care through the framework of the NHS

Providing palliative care services usually for people, whose estimated survival time is 2 years or less

Providing $82 \%$ of outpatient care and $35 \%$ of emergency care by the public sector care and $62 \%$ of emergency care Operational planning in 2008-2009

Providing about $18 \%$ of outpatient by the private sector

Providing health services at 3 levels.

Providing various types of palliative care services, such as outpatient care, home care, daycare, clinics, hospital support team, the Ministry of Education, patient support groups, family support group after patients'

death, parent support groups, orphan support groups, and hospice care for the homeless.

Classification of palliative care services in 3 levels

Providing physical care, spiritual care, socio-cultural care and psychological care, and support for the patient's family and caregivers.

Full-time access to palliative care services, including telephone consultations or examinations by palliative care specialist nurses and doctors at patients' home

Providing specialty and general persistent palliative care
Information and research

\begin{tabular}{|l|l|l}
\hline $\begin{array}{l}\text { April 2013- Establishing the National End of Life } \\
\text { Care Intelligence Network }\end{array}$ & $\begin{array}{l}\text { June 1996 - Palliative care } \\
\text { population } \\
\text { Hospital }\end{array}$ & $\begin{array}{l}\text { The 2nd Edition of the standards } \\
\text { manual for healthcare in } \\
\text { cooperation with the Council for } \\
\text { Health Services Accreditation of } \\
\text { Southern Africa }\end{array}$ \\
\hline $\begin{array}{l}\text { Background Electronic Palliative Care Coordination } \\
\text { Systems within the palliative care system }\end{array}$ & $\begin{array}{l}\text { 2016- Publishing the report by } \\
\text { Hospis Malaysia, under the title of } \\
\text { Palliative Care Needs Assessment }\end{array}$ & $\begin{array}{l}\text { 2000- Launching national and } \\
\text { regional plans to improve care } \\
\text { quality and accessibility }\end{array}$ \\
\hline $\begin{array}{l}\text { Providing research projects in academic centers } \\
\text { and publishing scientific journals }\end{array}$ & $\begin{array}{l}\text { November 2015- Implementing } \\
\text { the accreditation process using } \\
\text { the electronic self-assessment tool }\end{array}$ \\
\hline $\begin{array}{l}\text { Holding congresses and scientific meetings } \\
\text { tmproving the research capacity in the field of } \\
\text { palliative care }\end{array}$ & $\begin{array}{l}\text { 2010- The evaluation of the } \\
\text { mentorship program }\end{array}$ \\
\hline $\begin{array}{l}\text { Assessing the quality of provided services } \\
\text { according to different indicators }\end{array}$ & & \\
\hline
\end{tabular}

